\title{
The Impact of Digital Learning on Hygiene Awareness of Children with Down Syndrome
}

\author{
Aml Gameel Aly El-morsy \\ Department of Kindergarten, Education College, \\ King Khalid University, Abha, Saudi Arabia
}

\section{ABSTRACT}

Recent years have witnessed major advances in digital learning to support children diagnosed with Down syndrome. Since DS children suffer from a deficiency in learning and cognitive development problems and social functions. Variety of hygienic skills have compact their daily lives, with the goal of enhancing their hygiene awareness and hygienic skills to practice. Hence, this study was conducted to investigate the impact of digital learning to reinforce hygiene awareness for children with Down syndrome. The participants of the present study were 6 children with DS. The results have discussed the findings. The study targeted on the usability of DL. The sample enclosed DS children who are minimally effective communicators who need activities that are highly structured and sequenced information. The results showed an encouraging impact of the DL in supporting DS children to reinforce hygiene awareness.

Keyword: Digital Learning (DL), Hygiene Awareness, Down Syndrome (DS) 


\section{مستخلص البحث}

دراسة بعنوان أثز التعلم الرقمي على الوعي الصحي لدى الأطفال المصابين بمتلازمة داون ، حيث هدفت الدراسة إلى التعرف على مدى فاعلية تأثير التعلم الرقمي على تعزيز الوعي الصحي للأطفال المصابين بمتلازمة داون ، وقد أجريت الدراسة على عينة تكونت من(T) الأطفال بمرحلة رياض الاطفال، و تثراوح اعمار هم ما بين (1_آ) سنوات تقريبا من للأطفال المصابين بمتلازمة داون، وقد أختبرت عينة البحث بطريقة عمدية من الأطفال ما قبل المدرسة ذوى متلازمة داون بحيث حققت الثروط الواجبة للعينة، وطبقت الدراسة المنهج شبه التجريبى، ومجموعة تجريبية واحدة، واستمرت التجربة لمدة ستة أسابيع. وأظهرت النتائج مدى فعالية التعلم الرقمي على الوعي الصحي لدى الأطفال المصابين بمتلازمة داون. الكلمات المفتاحـية : التعلم الرقمي، الوعي الصحى ، متلازمة داون 


\section{Introduction}

Digital learning could be a kind of learning that's expedited by technology or by educational follow that produces effective use of technology. It encompasses the applying of a large spectrum of practices. Nowadays, DL tools in learning session become a lot of widespread and extremely useful to support children in their learning. Referred to as Interactive Learning Systems (ILS), these systems are effective techniques and are counseled to be used as tools of coaching as a result of it can turn out higher outcomes than the normal approach (Johnson \& Rubin, 2011). Similarly, with technologies that led to the creation of wireless devices like phones that might support activity mobile.

Previous reviews of DL studies have provided encouraging results for using mobile devices to support teaching and learning mobile (Yordanova, 2007). It's a next stage or a replacement kind of DL through the utilization of mobile and movable devices and wireless network and communication technologies for teaching and 
learning. Whereas Ally (2009) declared that mobile learning is that the method of using a mobile device to access and study learning materials and to communicate with children. The mobile learning is that the type of education that provides an oversized variety of learning opportunities on the strength of incorporates the multifunctionality of mobile devices.

The children with Down's syndrome suffer from a deficiency in learning and development. Such children tend to be less coordinated and have lack of sufficient muscle tension relief, creating it tough for them to try and do everyday tasks and to interact in activities like different children. Congenital disorder children additionally suffer from memory deficit, significantly in the basic cognitive process what has been spoken by others. They even have difficulties to obviously specific their inner thoughts with words verbally and do easy tasks (Ally, 2009). Children with mongolism would like explicit approaches in their learning. Also, they need plenty of repetition over an extended amount. Therefore, some approaches that do solely give regular apply however additionally incorporate 
selection corresponding to taking part in image word games, using phonics software package program, such DL could also be used and should serve to supply durable constructive outcomes for children with down syndrome (Moni \& Jobling, 2000).

Hygiene is an important a part of health; the children lose their lives because of diseases caused by improper hygiene. Hygiene awareness is one in each of the main problems for children with Down's syndrome. Hygiene awareness is crucial for eliminating diseases. Hence, with intentions of decreasing malpractices, varied serious DL has been developed hygiene awareness (Wattanasoontorn, Boada, Garcia \& Sbert, 2013).

The core of the study was to investigate whether or not designated DL has an effect on hygiene awareness for children with Down's syndrome and to investigate the necessity for conveyance information concerning hygiene. The research question developed keeping in mind these factors is as follows:

"How DL would increase hygiene awareness for children with Down syndrome?" 
The current research is considered as one of the significant studies in the field of DL of DS. The study is a vital issue concerning the hygiene awareness which is the engagement of DS in an effective learning environment. So, the research examined the rise in the level of hygiene awareness on Down's syndrome children through DL.

\section{Literature review}

Technologies can modify children to know ideas, to have interaction in learning a lot of promptly, whereas conjointly improving educational techniques and facilitating the widespread sharing of information. Digital technologies can modify this in new and higher ways.

\subsection{Digital learning}

Digital learning is any educational follow that's effectively using technology to strengthen the children learning expertise. DL is powerful tools for improving the participation and engagements of disabled people in their learning process. DL encompasses a large spectrum of tools and follow, as well as using online and formative assessment, increasing focus and quality of teaching resources and time, online content and courses, 
applications of technology, adjusted package for children with special desires, learning platforms, providing access to high level and challenging content and instruction, and lots of alternative advancements technology provides learning. Especially, integrated learning is any time children learn through online delivery (Staker, 2011).

\subsection{Down Syndrome Children}

DS is a set of physical and mental tracks which is caused as a result of a chromosomal disorder (Aal-Edwan, 2015). Normally a person has 46 chromosomes; while DS determined by 47 chromosomes (Percy \& Schormans, 2006). This extra genetic material alters the course of development (Al-Edwan, 2015) and causes diverse impairments such as visual, hearing, cognitive, motor and communication (Feng et al, 2008). Therefore, individuals with DS have varying degrees of abilities, skills, behavior and physical development. However, DS learning deficits result from different learning styles rather than learning impediments. DS people have a numerous disability appear as physical and cognitive characteristics that need to be identified serious attention and helpfulness when it comes 
to their education or other aspects of their life (Faragher \& Brown, 2005). As a general rule, students with DS need activities that are highly structured and sequenced, small amounts of information presented at a time and a good reward system (DASWM, 2015).

The children with Down syndrome are one of the groups of the children who suffer from cognitive development problems and social functions. Although, they typically show a delay in language. Those suffering from Down syndrome, despite having serious retardation problems, they usually have a good character and are happy, loving, and humorous. They are also able to adapt well to the community (Levis et al., 14).

Nevid (2012) also stated that children with Down syndrome suffer from deficiency in learning and development. Such children tend to be less coordinated and have lack of sufficient muscle tension relief, making it difficult for them to do everyday tasks and to engage in activities like other children. Down syndrome children also suffer from memory deficit, particularly in remembering what has been spoken by others, making it difficult for 
them to learn in school (Williams et al., 2005). They also have difficulties to clearly express their inner thoughts with words verbally, but most of them are able to learn how to read, write, and do simple arithmetic tasks after they have received proper education and good care (StoelGammon, 2001). Most of the positive improvements in the quality of life of these children with Down syndrome are a result of the strong support from their learning.

\subsection{Importance of Digital learning for DS}

Children with DS have the right to be educated and to be given appropriate supports to enable them to learn effectively. Nowadays, DL in learning session becomes more popular and very helpful to support children in their learning. Known as this system is developed to assist children in various ways (Baldwin \& Sabry, 2003). Children with Down syndrome are not same like normal children, thus they need to aid for learning. This coincided with the statement of Bennetts \& Flynn (2002) who mentioned that the existing modern classrooms do not provide adequate learning environment for children with special needs. Iarocci et al., (2006) stated that such named 
The Learn at Play Program (Lapp) may be beneficial and may serve to provide long-lasting constructive outcomes for children with Down syndrome, as well as Moni and Jobling (2000) stated that developing skills in Down syndrome children requires a lot of repetition over an extended period. Therefore, some approaches that do solely give regular apply however additionally incorporate variety corresponding to taking part in image word games, using phonics package program, and dealing with an educator should be adopted.

\subsection{The advantages of Digital learning for DS}

Children with DS have strengths as visual learners and find it difficult to learn from listening alone. DL can provide a source of both visual and auditory stimulation.

DL provides an environment where children can be in control and with practice can work unsupported, developing their self-esteem and independence. DL is able to present infinite chances to try the same activity, reproducing the exact experience over and over again and providing tireless positive feedback in the form of animations, music and sound effects. It can provide 
activities that are tailored to the individual child's level of skill in a specific area, creating an errorless learning experience. This means that the child is supported by the software, in order to achieve repeated success. Software can be programmed to respond to the child's input and modify the way in which it presents subsequent activities. DL can be carefully programmed to meet individual needs and teaching activities can be graduated in very small stages. DL can be used to develop Down syndrome children. Children with DS, like neurotypical children, are growing up with extensive exposure to DL. DL related devices have the potential to help these children in education and independent living. Most of the software system, games, and websites that children with mongolism act with are designed considerately of their special needs.

\subsection{Using of Digital Learning on Hygiene Awareness of DS}

DL offers a wide range of educational opportunities that could not be achieved in traditional face-to-face forms of learning and instruction (Kalyuga \& Liu, 2015). DL enhance efficiency of learning and offer more diversified 
learning experiences without limitations of time, space and place (Lee \& Hung, 2015; Noroozi, Busstra et al., 2012). The instruction with DL can also be delivered by the use of instructional clips, which present the instructional message to the DS auditory and visually. Each clip involves a concise statement of a crucial step in the hygiene awareness. The sounds of the clips verbalize and reason the connections between the different elements of the domain-specific knowledge. By clearly arranging the steps and providing, verbalizing and reasoning thought models, the instructional messages may prime appropriate organizational processing.

This study aimed to investigate how hygiene awareness enriched with using DL through instructional clips, online guidance, content structuring, and a collaboration tool, as a combination, can be designed to enhance hygiene awareness of children with Down syndrome. The ultimate goal is to reframe instructional design in DL in DS, through direct application DL. 


\section{Research Questions}

Therefore, the following research questions are formulated to test the effects of DL including instructional clips, online guidance, structuring of content and a collaboration tool on hygiene awareness of DS:

a) What are the hygiene awareness skills necessary for DS?

b) What is the impact of using digital learning applications in improvement some hygiene awareness skills for DS?

\section{Research Hypotheses}

To address the following hypotheses are constructed:

1. There are statistically significant differences between the mean ranks of the experimental group on the pre/post digital learning application in favor of the post application.

2. There are no statistically significant differences between the mean ranks of the experimental group between the post application and the following application. 


\section{Method}

\subsection{Sample}

The participants of the present study were 6 children with DS registered in one among special needs center in Hurdada, Egypt, aged between 5-6 years nearly. The DS children participated from the 9:00 a.m. to 10:00 a.m., severally. The DS children are purported to enhance their hygiene awareness skills.

\subsection{Materials}

\subsubsection{Application Description}

The major purpose of the study is to get whether or not DS children would enhance some hygiene awareness skills. For the study researched a sample of four DS children, they have been asked to use an application. Throughout experimentation, the sample was asked to use the applications offered on YouTube. At the tip of the treatment, participants were evaluated. The application includes numerous activities to apply and consolidate hygiene awareness of DS children. Selecting these tasks supported variable within the level of issue. 
Additionally, these tasks are in English language. By distinguishing their areas of interest and their patterns of eye movement, we are going to be higher privy regarding children preferences. This successively can contribute to a clearer understanding of children's desires. Also, they create communication fun, like instructional clips on the device. Tap an image and therefore the application speak. Every image will result in another screen of images. The most purpose of the app is to help children in enhancing some hygiene awareness. This application supports solely the English language and emphasizes supporting verbal communication. The appliance focuses on DL settings for hygiene awareness skills for DS App which aid also as everyday communication in non-formal settings corresponding to reinforce the hygiene awareness skills, the main menu of hygienic skills clips as shown in Figure 1. 


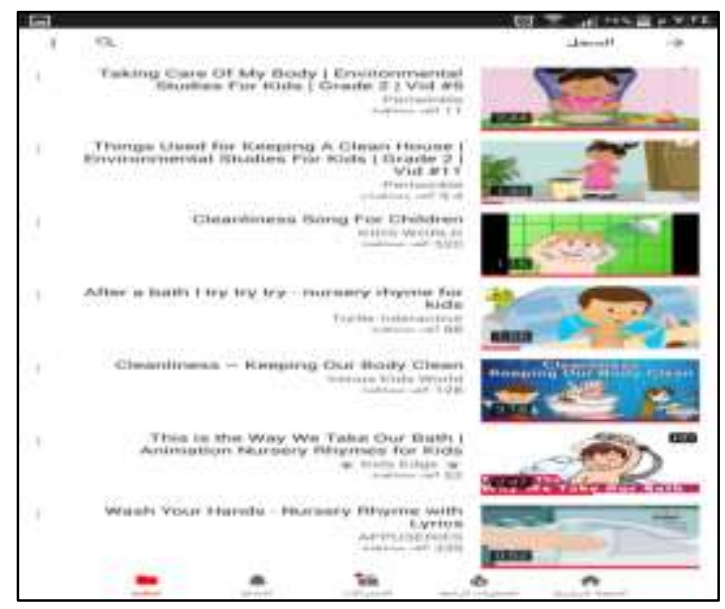

Figure 1. "DL App"

DL application includes 25 clips. The clips were delimited to reinforce the hygiene awareness skills as following included instructional clips within the application. The clips of application are divided into 10 main hygiene awareness clips. Moreover, DS children will tap and select any image during this application. Each clip helps the DS children to reinforce hygiene awareness as shown in Figure 2.
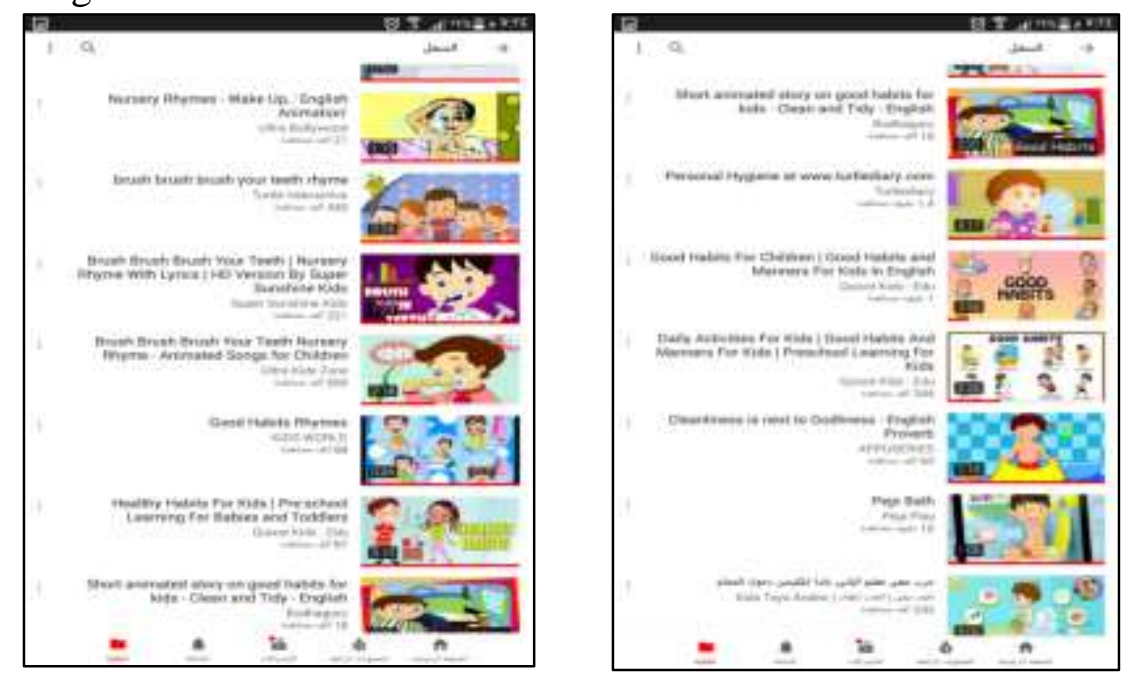

Figure 2. Hygienic Skills Clips 
As shown in Figures, provides features: the main menu of hygienic skills clips: This DL app is a grouping of the hygienic skills clips, divides into 10 sub-clips reminiscent of cleanliness, self-care, hygienic habits. Every sub- clip has its images and audio cues consequently e.g. if a user chooses a clip, the list of a various form are shown wherever DS children will tap each clip and watch it that related to the hygienic skills as follows:

1-Washing Hands: this screen, as shown in three clips, include different hygienic skill about washing hands where DS children can tap the clip and watch each clip that acquired to pay attention as shown:

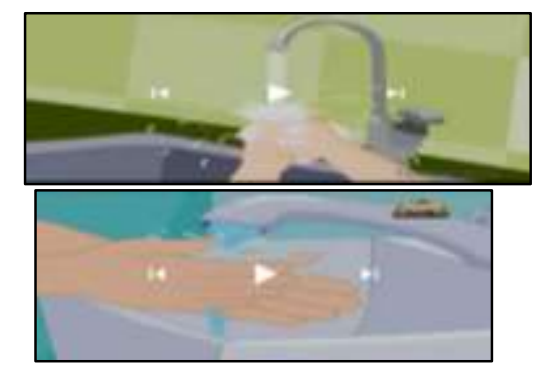

Clip 1.

Clip 2.

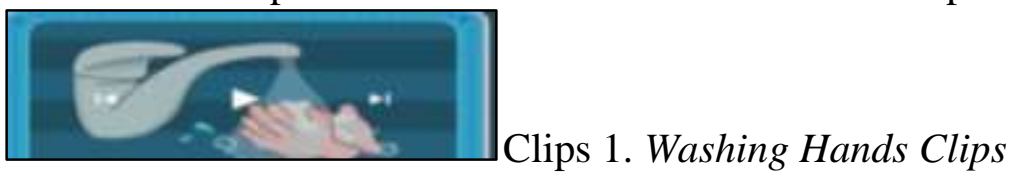

Clip 3.

2- Washing Face: this screen, as shown in two clips, include different hygienic skill about washing face where DS children can tap the clip and watch each clip that acquired to pay attention, as shown: 

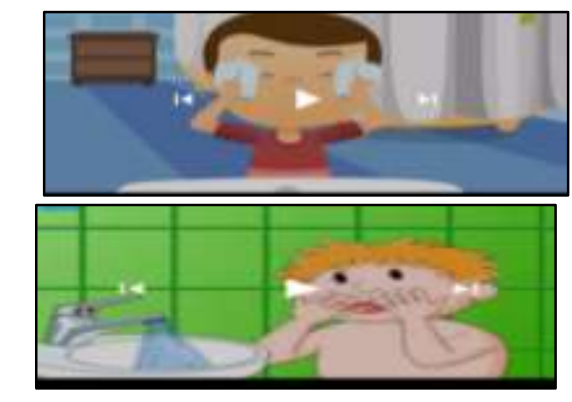

Clip 1.

Clips 2. Washing Face Clips

Clip 2.

3- Bathing: this screen, as shown in four clips, include different hygienic skill about bathing where DS children can tap the clip and watch each clip that acquired to pay attention, as shown:

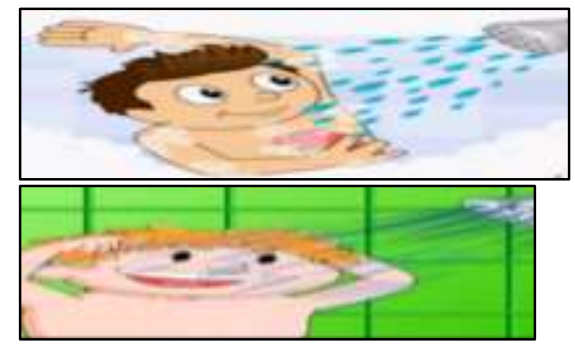

Clip 1.

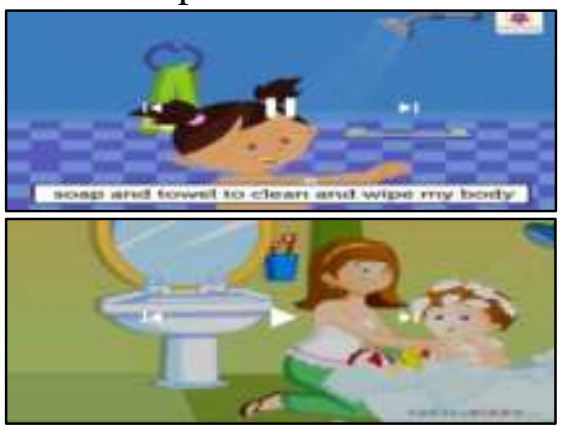

Clip 3.
Clip 2.

\section{Clip 4.}

Clips 3. Bathing Clips

4- Brushing Teeth: this screen, as shown in three clips, include different hygienic skill about brushing teeth where DS children can tap the clip and watch each clip that acquired to pay attention, as shown: 


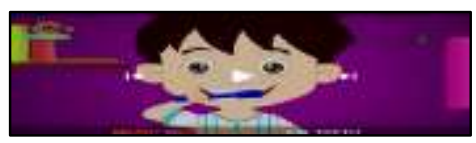

Clip 1.

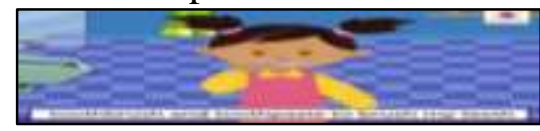

Clip 3.

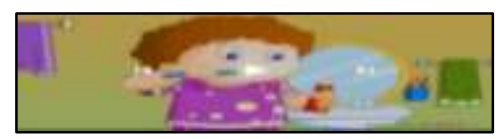

Clip 2.

Clips 4. Brushing Teeth Clips

5- Combing Hear: this screen, as shown in four clips, include different hygienic skill about combing hear where DS children can tap the clip and watch each clip that acquired to pay attention, as shown:

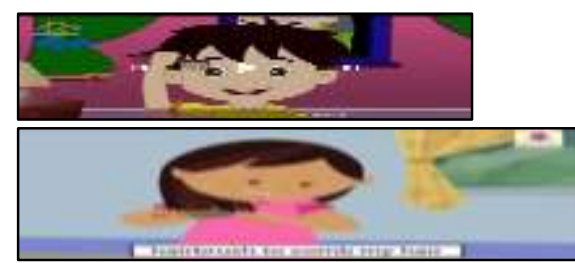

Clip 1.

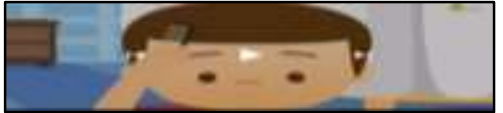

Clip 1.
Clip 2.

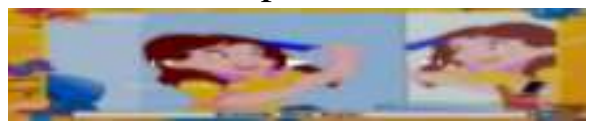

Clip 2.

Clips5. Combing Hear Clips

6- Cutting Nail: this screen, as shown in one clip, include different hygienic skill about cutting nail where DS children can tap the clip and watch each clip that acquired to pay attention, as shown:

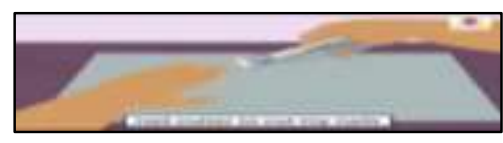

Clip 6. Cutting Nail Clip

7- Using Towel: this screen, as shown in one clip, include different hygienic skill about using towel where DS children can tap the clip and watch each clip that acquired to pay attention, as shown: 


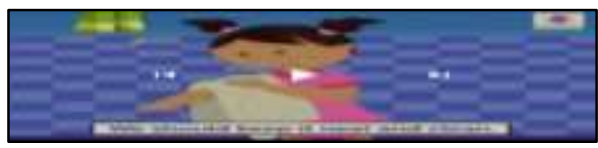

Clip 7. Using Towel Clip

8- Getting Rid of Rubbish: this screen, as shown in one clip, include different hygienic skill about getting rid of rubbish where DS children can tap the clip and watch each clip that acquired to pay attention, as shown:

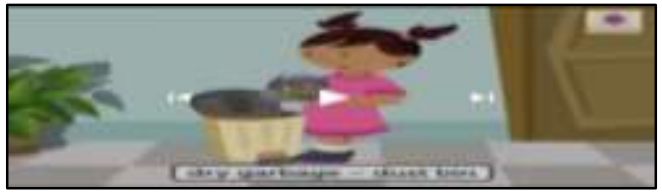

Clip 8. Getting Rid of Rubbish Clip

9- Healthy Eating : this screen, as shown in four clips, include different hygienic skills about Healthy Eating where DS children can tap the clip and watch each clip that acquired to pay attention, as shown:

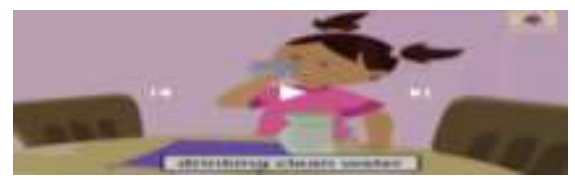

Clip 1.

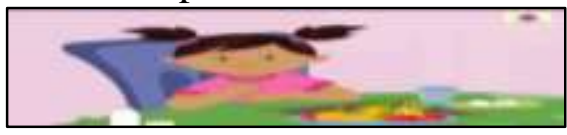

Clip 3.

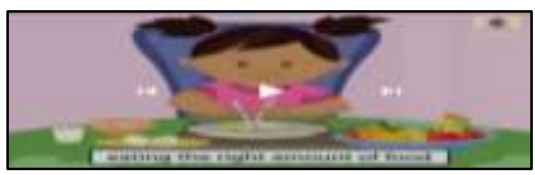

Clip 2.

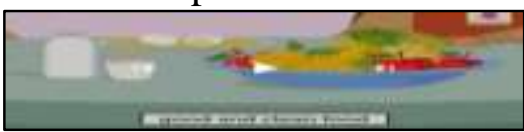

Clip 4.

Clips 9. Healthy Eating Clips

10 - Exercise: this screen, as shown in two clips, include different hygienic skills about exercising where DS children can tap the clip and watch each clip that acquired to pay attention, as shown:

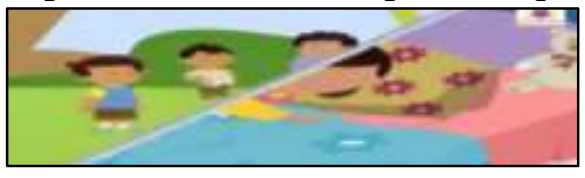

Clip 1.

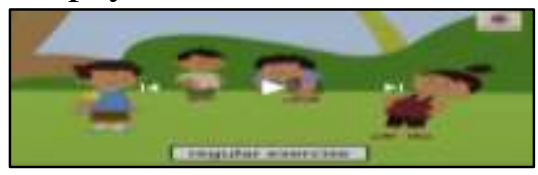

Clip 2.

Clips10. Exercising Clips 
The researcher conducted the study employing a DL app and their implication on hygiene awareness of children with Down syndrome with using completely different and designated techniques aiming at developing some hygienic skills of DS children's ability. Consistent with the implementation of the DL app, all participants performed the task properly within the application.

In the second part, we tend to use observation within the study. The appliance that has been used for this study is barely free English application offered for DS children within the YouTube.

\subsubsection{Duration of the Implementation}

Time of the implementation lasted for six weeks. Thus, all the experimentation took twenty-four sessions (twentyfour hours). The primary session enclosed the interactive and targeted DL app clips and elements of the app: "hygiene awareness skills" within the application. DS children had been concerned during a type of activities that were targeted to promote their hygiene awareness skills.

\subsection{Research Design}

This study is conducted using a quasi-experimental research design with an independent variable for one group 
(the experimental group) children who exposed to DL app activities clips.

\subsection{Instrumentation}

To investigate the impact of using DL app in developing hygiene awareness for children with Down syndrome; the researcher dealt with the following instruments:

1. A DL app activities clips to reinforce hygiene awareness for children with Down syndrome.

2. Assessment Checklist.

\subsection{Procedures and Experimental Design}

The implementation of DL app activities introduced a variety of hygienic activities to involve the participants in individual work. At the end of the sessions enclosed assessment and evaluation. Their teacher filled out these children's questionnaires as a result of their acquirement skills is restricted. The aim of those sessions was to prepare DS children for the intervention. The researcher has conducted the study using the DL app activities.

The participants of the study were trained to use YouTube app activities of hygiene awareness. The DS children were additionally instructed several hygiene awareness skills through using DL app activities which had 
made enhancing hygiene awareness skills activities a lot of pleasant. The training was expected to cause a modification in their hygiene awareness skills of DS children. Generally, DS children were requested to use DL application activities for 30 minutes in each session for six weeks, four sessions per week. The foundations that outlined the DL app assumed in our experiments are the following:

The DS children are considered to have learned hygiene awareness skills when they react whereas watching the clip.

Instant watching the clip and image display when an object is encountered; application remains silent for a minute when the child touches an object's image on the smart device, after the one-minute break the object can be identified again; \& up to $30 \mathrm{~min}$. the session with the DL application activities.

$>$ The participants were asked to accomplish ten major categories of clips.

$>$ The DL application was implemented in two sections as follows: 
1- Baseline section refers to the standing of the topic before the intervention. Recurrent measurements of the variable are taken to function an effect and alter to examine the changes that occur with intervention. This section is conducted while not the utilization of prompts or reinforcements.

2- Intervention section represents the implementation of the intervention. Throughout this section, recurrent measurements of the variable, using equivalent measures as assessment listing and a written account of observations, are obtained to assist verify if any modification has occurred. This enables determinant if the intervention is effective or not. The sessions happened during a natural learning setting, at a table, wherever the researcher and the participants would sit next to every alternative. DL app was put in on a sensor device, given the provision for the aim of evaluation; the sessions were carried per week, using the DL app activities. Only if children with DS have a predilection for visual media, the DL app was been participating and motivating. 


\subsection{Assessment Checklist}

This assessment, that is especially helpful in adjudging hygiene awareness of children with down.

\subsection{Purpose of the assessment checklist:}

To determine the need for assessment checklist, the instrument was specifically designed to provide information to answer the study question: What is the impact of using digital learning applications in improvement some hygiene awareness skills for DS?

It gave the researcher valuable insights to adjudge DS children's use of the DL app.

\subsection{The content of the assessment checklist}

The assessment checklist was composed of two hygiene areas - in ten strands (Personal Hygiene \& Domestic Hygiene) - purposefully designed to measure jury's level of agreement concerning the assessment checklist necessary for DS. High scores indicated a higher level of the agreement while low scores indicated lower levels of agreement. The overall calculated score that determined the need for assessment checklist is shown in Table 1.

The assessment checklist had to be rated by the panel of jury according to a rating scale containing three degrees of 
importance alternatives: important, neutral and unimportant. Furthermore, the panel of a jury was required to add to the list any hygiene areas they considered important is shown in

\begin{tabular}{|c|c|}
\hline Hygiene Areas & Hygiene Indicators \\
\hline Personal Hygiene & $\begin{array}{l}\text { Respondents for Washing Hands } \\
\text { Respondents for Washing Face } \\
\text { Respondents for Bathing } \\
\text { Respondents for Brushing Teeth } \\
\text { Respondents for Combing Hear } \\
\text { Respondents for Cutting Nail } \\
\text { Respondents for Healthy Eating }\end{array}$ \\
\hline Domestic Hygiene & $\begin{array}{l}\text { Respondents for Using Towel } \\
\text { Respondents for Getting Rid of Rubbish } \\
\text { Respondents for Exercise }\end{array}$ \\
\hline
\end{tabular}

Table 1.

Table 1. The content of the assessment checklist

The researcher used assessment listing as assessment. Additionally, the researcher required to possess a written account of observations throughout the children's work that provided:

- A mechanism for fair and consistent feedback to the DS children.

- A way of creating certain that each DS child was being observed in a timely way. 
- Assurance of the knowledge from observations wasn't forgotten over time.

\subsection{Validity of the assessment checklist}

In order to establish content validity for the assessment checklist, a group of jury members approved its validity and its suitability for DS children. These experts were asked to review the items on the list and to state if given items were relevant or not. They were asked whether there were any important points that were not included in the list. They approved it and suggested modifying some components. By basing the list on best practices from the literature, construct validity was established.

\subsection{Reliability of the assessment checklist}

To determine the reliability of the assessment checklist, inter-rater reliability was used. Inter-rater reliability was calculated by finding the percentage agreement between two raters. The percentage agreement was calculated by dividing the number of times in agreement by a total number of ratings. The inter-rater reliability of the assessment checklist was $(89.7 \%)$ which is highly reliable.

\section{Results}


Our goal for this study was to examine if DS children may enhance hygiene awareness through using DL clips. To assess a topic progress it's necessary to perform measurements. These measurements are acquired through direct observation and may be created before and through the intervention with regularity (hours, days, weeks). During this section, we tend to discuss the information collected, and what were the results of every part and of the research as an entire. On the primary sessions supported the result of the previous session, the primary trial was given while not prompt, though it absolutely was a step back from the previous session, additionally showed us that there was an improvement compared to the first session of the previous day. Consequent sessions have given additional prompt properly. On the section, DL activities clips performed each session properly, the hygiene awareness was thought of acquired and therefore the intervention section was complete as shown in Figure3

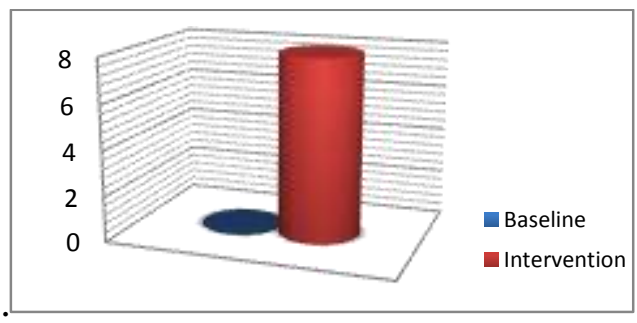


Fig. 3 Section /Session

Although, it absolutely was a good result, it will mean that DS children memorized the hygiene awareness clips from the previous session, which is why we tend to stipulate that there had to be two correct sessions in at some point to take into account the hygiene awareness skills as acquired. The study pointed to many positive functions of the DL app and its impact on rising learning skills in hygiene awareness of DS children as shown in Figure 4.

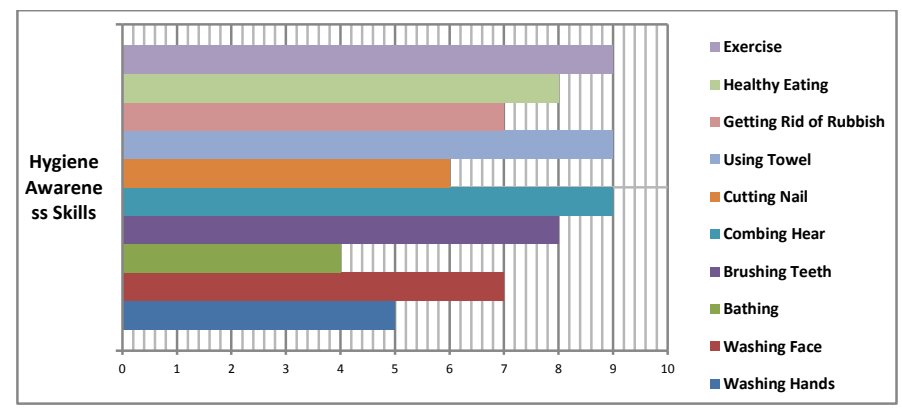

Figure .4 Hygiene Awareness Skills

Although, it absolutely was a good result, it will mean that DS children memorized the hygiene awareness clips from the previous session, which is why we tend to stipulate that there had to be two correct sessions in at some point to take into account the hygiene awareness skills as acquired. The study pointed to many positive functions of the DL app and its impact on rising learning skills in hygiene awareness of DS children as shown in Figure 2. 
The results of the study:

1. The study proved the validity of the first hypothesis which states that, there are statistically significant differences between the mean ranks of the experimental group on the pre/post digital learning application in favor of the post application.

2. The study proved the validity of the second hypothesis which states that, there are no statistically significant differences between the mean ranks of the experimental group between the post application and the following application.

\section{5- Discussion}

Consistent with the research findings involving DS children, results of this study incontestable that the recommended DL. It is an effective means that of rising hygiene awareness for DS children. The DL app perceived to have a major impact. On measurement, there's sturdy empirical proof suggesting that DL contributed to the development of participants' hygiene awareness. The DS children who received DL considerably and systematically performed on measures of hygiene awareness skills development. These results indicate that DL is an efficient 
means that of DS children learning a way to practice hygiene awareness activities accurately throughout their learning expertise. These findings recommend that the utilization of DL is effective as a tool and are in keeping with the outcomes of the research that was conducted antecedently. Findings showed that DL is effective in enhancing hygiene awareness. This study confirmed what has been incontestable by others researchers that using DL is an efficient mean that of developing hygiene awareness skills of children with DS. Moreover, the current study evidenced the effectiveness of DL to reinforce hygiene awareness of DS children.

\section{6- Conclusion}

The research has important contributions, to advance the hygiene awareness of the DS children. It's to facilitate to modify hygienic skills for those children who are suffering from DS. The DL was applied to a sample of 6 DS children. The results of the study reveal the positive outcome, satisfactory usability and improved hygiene awareness of DS children. Efficiency was established using the DS children DL that DS children have the benefit of DL in enhancing hygiene awareness skills. 


\section{7- Recommendations}

Although we consider DL successful and that it fulfilled our goals in reinforcing hygiene awareness. Based on the results of the current study, the following recommendations are stated:

- DL should be emphasized in teaching and learning different features of the hygiene awareness. It includes the use of various activities directed to the DS children. It makes learning easy for the DS children to absorb knowledge and develop hygiene awareness skills.

- Future research is needed to determine if other programs are effective as DL in helping children with DS's skills. They acquire some of the key foundation skills necessary for their hygiene awareness.

- DL is also needed to be used with the learning stages. DL is an engaging and developmentally appropriate method that is relevant at all stages. 


\section{References}

1) Al-Edwan, S. (2013). Developing the mathematical skills among a sample of Down syndrome by education. Journal of Education and Practice, Vol. 4, No. 16, pp. 145-156.

2) Stoel-Gammon, C. (2001). Down Syndrome Phonology: Developmental Patterns and Intervention Strategies. Down Syndrome Research and Practice, Vol. 7, No. 3, Pp. 93100.

3) Johnson, D.A. \& Rubin, S. (2011). The effectiveness of Interactive Computer-based Instruction: A Review of Studies Published between 1995 and 2007. Journal of Organizational Behavior Management, Vol. 31, No. 1, Pp. 55-94.

4) Levis, D.M., Harris, S. N., Whitehead, R., Moultrie, Duwe, K., Rasmussen, S.A. (2012).Women's Knowledge, Attitudes, and Beliefs about Down Syndrome: A Qualitative Research Study", American Journal of Medical Genetics, Part A.

5) Deutsch, S., Deborah. (2006). Introduction to Special Education: Teaching in an Age of Opportunity ( $5^{\text {th }}$ ed). Boston: Pearson Education Inc., 149183. 
6) Digital Learning: Data, Trends, and Strategies You Need to Know. Retrieved 2017-10-04. www.schoology.com.

7) Faragher, R., Brown, R. I. (2005). Numeracy for adults with Down Syndrome: It's a matter of quality of life, Journal of Intellectual Disability Research, Vol. 49, No. 10, pp. 761-765.

8) Feng, J., Lazar, J., Kumin, L., Ozok, A. (2008). Computer usage by young individuals with Down Syndrome: an exploratory study, in Proceedings of the 10th International ACM Sigaccess Conference on Computers and Accessibility, PP. 35-42 Halifax, Nova Scotia, Canada.

9) Iarocci, G., Virji-Babul, N. \& Reebye, P. (2006).The Learn At Play Program (LAPP): Merging Family, Developmental Research, Early Intervention, and Policy Goals for Children with Down Syndrome, Journal of Policy and Practice in Intellectual Disabilities, Vol. 3, No. 1, Pp. 1121 .

10) Kennedy, G.E., Judd, T.S., Churchward, A., \& Gray, K. (2008). First Year Studentse Experiences with Technology: Are they Really Digital Natives, Australasian Journal of Educational Technology, Vol. 24, No. 1, Pp. 108-122. 
11) Staker, H. (2011).The Rise of K-12 Blended Learning: Profiles of Emerging Models (Mountain View, CA: Innosight Institute, p. 3. For further examination of the spectrum of blended learning, see Keeping Pace with $\mathrm{K}-12$ Online Learning, iNACOL.

12) Traxler, J. (2007). Defining, Discussing and Evaluating Mobile Learning: The Moving Finger Writes and Having Writ, The International Review of Research in Open and Distance Learning, Vol. 8, No. 2 .

13) Nevid, J.S. (2012). Psychology: Concepts and Application, Wadsworth Publishing Company.

14) Yordanova, K. (2007). Mobile Learning and Integration of Advanced Technologies in Education, Proceedings of the 2007 International Conference on Computer Systems and Technologies, ACM.

15) Moni, K.B. \& Jobling, A. (2000). LATCH-ON: A Program to Develop Literacy in Young Adults with Down Syndrome, Journal of Adolescent \& Adult Literacy, Pp. 40-49.

16) Williams, K.R., Wishart, J.G., Pitcairn, T.K. \& Willis, D.S. (2005). Emotion Recognition by Children with 
Down Syndrome: Investigation of Specific Impairments and Error Patterns, Journal Information, Vol. 110, No. 5.

17) Kalyuga, S., \& Liu, T. C. (2015). Guest editorial: Managing cognitive load in technology-based learning environments, Educational Technology \& Society, 18(4), $1-8$.

18) Kollar, I., Ufer, S., Reichersdorfer, E., Vogel, F., Fischer, F., \& Reiss, K. (2014). Effects of collaboration scripts and heuristic worked examples on the acquisition of mathematical argumentation skills of teaching students with different levels of prior achievement. Learning and Instruction, 32, 22-36 .

19) Kukulska, H., Traxler, J. \& Pettit, J. (2007). Designed and User-Generated Activity in the Mobile Age, Journal of Learning Design, Vol. 2, No. 1, Pp. 52-65 .

20) Baldwin, L. \& Sabry, K. (2003). Learning Styles for Interactive Learning Systems, Innovations in Education and Teaching International, Vol. 40, No. 4, Pp. 325-340 .

21) Bennetts, L. \& Flynn, M. (2002). Improving the Classroom Listening Skills of Children with Down Syndrome by using Sound-Field Amplification, Down Syndrome Research and Practice, Vol. 8, No. 1, Pp. 19-24. 
22) Lee, L. T., \& Hung, J. C. (2015). Effects of blended e-learning: A case-study in higher education tax learning setting. Humancentric Computing and Information Sciences, 5, 1-15.

23) Ally, M. (2009). Mobile Learning: Transforming the Delivery of Education and Training, Athabasca University Press .

24) Najimi, A.L. (2009).Why and how Mobile Learning can Make a Difference in the K-16 Classroom?, Proceedings of Society for Information Technology \& Teacher Education International Conference, Editors: I. Gibson et al., Chesapeake, VA: AACE, Pp. 2903-2910 . 25) Noroozi, O., Busstra, M. C., Mulder, M., Biemans, H. J. A., Tobi, H., Geelen, M. M. E. E., \& Chizari, M. (2012). Online discussion compensates for the suboptimal timing of supportive information presented in a digitally supported learning environment, Educational Technology Research and Development, 60, 193-221.

26) Percy, M. and Schormans, A. (2006). Down Syndrome, Journal on Developmental Disabilities, Vol. 12. No. 1, pp. 1-6. 
27) Doneva, R., Kasakliev, N., \& Totkov, G. (2007). Towards Mobile University Campuses, Communication \& Cognition. Monographies, Vol. 40, No. 1-2, Pp. 67-75 .

28) Special Needs and Assistive Technology Exhibitions in the UK. (2004). Retrieved 9 June 2004, from http://www.inclusive.co.uk/exhibitions/index.shtml

29) Teaching with Digital Technologies". 2017. www.education.vic.gov.au. Retrieved -06-18.

30) Wattanasoontorn, V., Boada, I., Garcia, R. \& Sbert, M. (2013). Serious games for health. Entertainment Computing, 4(4), 231-247. 